\title{
Student Evaluations: Synchronous Tripod of Learning Portfolio Assessment—Self-Assessment, Peer-Assessment, Instructor-Assessment
}

\author{
Jenna-Lynn Senger, Rani Kanthan* \\ Department of Pathology and Laboratory Medicine, University of Saskatchewan, Saskatoon, Canada \\ Email: "rani.kanthan@saskatoonhealthregion.ca
}

Received December $14^{\text {th }}, 2011$; revised January $10^{\text {th }}, 2012$; accepted January $29^{\text {th }}, 2012$

\begin{abstract}
Background: Learning portfolios are increasingly being introduced in higher education including undergraduate and postgraduate medical education. Due to their highly personalized nature, creation of an assessment tool that accurately reflects the value for the learner of the "work" created is challenging, and has prevented a more widespread use of this valuable tool. Innovation \& Evaluation: Forty-one physical therapy students were asked to create a learning portfolio as a component of their pathology course. This collection of evidence of learning was evaluated at the midterm and final examination by a synchronous tripod of assessors-the "self", a peer, and the instructor to provide a formative and summative evaluation. Results: Grades awarded by the three assessors were more similar at the end of the semester when compared with those at the midterm. A quantitative and qualitative satisfaction questionnaire was additionally given to students to determine the usefulness of this educational activity. Though the majority of students responded favourably, with notable self-reported improvements in communication, team-work, and professional growth, primary challenges included negative perceptions related to increased time commitment, student and teacher-related stress, and uncertainty regarding the value and the immediate and long-term relevance of this creative learning activity. Conclusion: Reflection on our study authenticates that the combination of formative and summative evaluations from such tripod assessments of learning portfolios is particularly suited for explicit inclusion in higher educational programs including medicine and allied health professionals. We recommend learning portfolios as a creative learning tool and assessment tool in higher education.
\end{abstract}

Keywords: Learning Portfolio; Self-Assessment; Peer-Assessment; Instructor-Assessment; Tripod Assessment

\section{Introduction}

Portfolios were traditionally created by artists and architects to demonstrate their high quality of work to potential customers (van Tartwijk, Driessen, van der Vleuten, \& Stokking, 2007). These "ability showcases" have evolved and are slowly being adopted by the educational community at large. Today, learning portfolios (LP) are integrated in the medical and allied health professional curriculums of undergraduate, post-graduate and continuing professional life-long learning for re-validation of doctors for a continuing licence (Teng, 2007). Over the past twenty years, learning portfolios have slowly been gaining popularity in higher education (van Tartwijk, Driessen, van der Vleuten, \& Stokking, 2007), with professional colleges recognizing the unique combination of self-reflection, self-direction, self-analysis, and self-discipline required to create and maintain such a personalized collection. The autonomy of portfolio development encourages students to reflect on personal experiences and concerns with a self-directed reflection that promotes a sense of ownership and motivation (Driessen \& Norman, 2008). Due to this "personalization", difficulties in assessment arise with a struggle between standardization and reliability vs. holistic personalization and validity that limits its widespread ap-

\footnotetext{
*Corresponding author.
}

plication in medical education (Driessen, Overeem, van Tartwijk, van der Vleuten, \& Muijtjens, 2006; Amsellem-Ouazana, van Pee, Godin, 2006; David, Davis, Harden, Howie, Ker, \& Pippard, 2001).

\section{Aim}

The aim of this study was to introduce, implement and consider the drivers and barriers of learning portfolios through the tripod of self-, peer-, and instructor-assessment. In their $24^{\text {th }}$ guide to medical education, the Association for Medical Education in Europe (AMEE), evaluated the use of portfolios as a method of student assessment (David, Davis, Harden, Howie, Ker, \& Pippard, 2001). Their five suggestions for standardization of portfolio assessment were incorporated in the individual-, peer-, and instructor-assessment strategies employed in this study. These recommendations include

1) "Same portfolio's units of evidence are assigned to all students" - $\mathrm{a}$ list of required material to be included in the portfolios was distributed to all students.

2) "Tasks and criteria for assessment are defined and made clear".

3) "Instructions to students provide clear guidelines"- students received a comprehensive introduction to the portfolio project at its onset and were encouraged to provide feedback 
both formally via satisfaction questionnaires and informally in the extended learning environment (contact classroom time + web-based interactions).

4) "The portfolio reading process and rating of material follow standardized guidelines"-identical assessment tools for all three assessors included quantitative assessment based on a specially designed 5-point Likert scale and qualitative assessment guided by open-ended questions.

5) "The probing in an oral review of the portfolio with the student follows standardized guidelines"-due to the tripod nature of the assessments, students interacted with their assessors throughout and upon the completion of the course with constant formative and summative feedback opportunities.

\section{Materials and Methods}

The physical therapy program at the University of Saskatchewan transferred from a Bachelor's degree to a Master's Program. This was accompanied by major curricular renovations that included the construction of ten separate modules. The second module included a twelve-week (January to April) specially designed pathology course with 2.5 hours of contact class time and 5 "discovery hours" per week. "Discovery hours" are specific hours for self-directed learning without instructor supervision. A learning portfolio (LP) was designed to specifically incorporate assessment of both affective and course-specific objectives for the discovery hours of this course. The project was developed incorporating the five AMEE suggestions for standardization of portfolio assessment, as outlined above (David, Davis, Harden, Howie, Ker, \& Pippard, 2001). After a pilot run for one year, the LP as an assessment tool was formally researched and analyzed prospectively. 41 students enrolled in this program participated in this study. Students were introduced to the concept of LPs including the purpose and focus of this activity, and were given an outline to guide their efforts. A semi-structured approach in alignment with the course objectives incorporated weekly mandatory entries to achieve maximum control of standardization for the portfolio content and process: the individual class quiz, the class group quiz, the group activity and a one-page self-reflection document. A template was given to aid students who had no prior experience in the self-reflective process. Students were further encouraged throughout the course to include evidence of their own learning and development. Suggested, voluntary entries included evidence of completion of the specially-designed online digital games or relevant and interesting news articles, a list of recommended websites or literary sources. Each week as the student completed another section of their "mandatory evidence", group activities provided students with the opportunity to discuss and to receive ongoing feedback on the contents and format of their learning portfolios. Of this voluntary material, students selected the work that best displayed their growth and learning over the semester for inclusion in their portfolio.

At the onset of the course, students collectively negotiated and decided on a mark breakdown, allotting their final grade between the portfolio and the midterm and final examinations. A formal summative tripod assessment of the portfolio by self, peer, and instructor was conducted at the midterm and final examinations, to enhance the portfolio's reliability. A specially designed assessment tool for the learning portfolio (Table 1) was created to standardize evaluations between the three assessors, as suggested by the outline five suggestions for portfolio
Table 1.

Self/peer/instructor-assessment tool for the learning portfolio.

This portfolio is well-structured, i.e. content is presented in the proper place, descriptions, analyses and learning objectives are easy to find.

1--------------2---------------3--------------4----------------5

This portfolio is complete, i.e. no required components are missing.

1-----------2-----------3----------4-----------5

This document is “clean” i.e. proper spelling, grammar, and sentence structures are used.

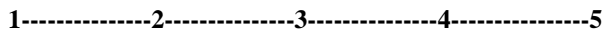

This portfolio shows evidence of critical self-reflection i.e. indicates both strengths and weaknesses.

1-------------2-------------3--------------4---------------5

Evidence that supports the analyses of strengths and weaknesses is included in this portfolio in a systematic and clearly evident fashion.

1-------------2--------------3--------------4---------------5

This portfolio has content beyond the guiding questions and instructions (without being a "shopping trolley").

1---------2----------3-----------4------------5

This portfolio shows evidence of steps taken to achieve the learning objectives.

1--------------2----------------3----------------4----------------5

Portfolio Strengths;

Portfolio Weaknesses;

Recommendations for Improvement.

assessment standardization (David, Davis, Harden, Howie, Ker, \& Pippard, 2001). These evaluations included a combined quantitative 5-point Likert-scale based assessment and eight open-ended qualitative questions. The final grade of the portfolio was calculated by determining the average of these three equally-weighted assessments.

Additionally, on alternate weeks, students were asked to fill out a brief qualitative and quantitative satisfaction questionnaire to provide feedback regarding their attitudes towards this learning experience that led to constant modifications and recommendations for the portfolio process and content as required. In total the questionnaire was repeated five times in the ongoing twelve weeks. At the midterm and final examination, a more comprehensive detailed questionnaire for formative feedback was collected (Table 2). All questionnaires were submitted anonymously thus reassuring students that their responses would have no effect on their graded marks.

\section{Results}

Forty-one students were enrolled in the 2010 Masters of Physical Therapy course at the University of Saskatchewan. At the beginning of the semester, the students decided that the learning portfolio should account for $50 \%$ of their overall final course grade, with the midterm and final examination each contributing 25\%. All three assessors used the semi-structured 5-point 7-question Likert scale (Table 1) to award a grade out of a possible 35 points and provided comments. At midterm examination, self-assessment ranged from $78 \%$ - 99\% (mean $86.1 \%$ ), peer-assessment from $69 \%$ - 92\% (mean 82.3\%), and instructor-assessment from $78 \%$ - 96\% (mean $87.1 \%$ ). At final examination, self-assessment ranged 69\% - 91\% (mean 82.5\%), peer-assessment from 69\% - 89\% (mean 83.7\%) and instructor-assessment from 70\% - 89\% (mean 81.3\%). As seen in Figures 1 and 2, the grades awarded by the three assessors were more closely related on the final evaluation when compared to 
Table 2.

Student satisfaction questionnaire.

\begin{tabular}{|c|c|c|c|c|c|c|}
\hline & \multicolumn{3}{|c|}{ Midterm } & \multicolumn{3}{|c|}{ Final } \\
\hline & 1,2 & 3 & 4,5 & 1,2 & 3 & 4,5 \\
\hline I like using Learning Portfolio as part of assessment for this course & 11 & 15 & 12 & 15 & 5 & 18 \\
\hline I liked the "partially" structured organization of the Learning Portfolio & 4 & 11 & 23 & 7 & 10 & 21 \\
\hline Portfolio development has improved my writing skills & 25 & 10 & 3 & 18 & 16 & 4 \\
\hline Portfolio development has improved my communication skills & 23 & 13 & 2 & 17 & 16 & 5 \\
\hline Portfolio development has made me more reflective about my thought processes. & 8 & 10 & 20 & 8 & 15 & 15 \\
\hline Portfolio development has improved my own learning and performance & 13 & 14 & 11 & 15 & 9 & 14 \\
\hline Portfolio development has helped me develop thoughts to concrete processes and products & 14 & 13 & 11 & 12 & 13 & 13 \\
\hline Portfolio development has helped me engage in useful reflection about my approach to this course. & 15 & 13 & 10 & 14 & 12 & 12 \\
\hline Portfolio development has enhanced my feeling of responsibility for monitoring my own progress & 7 & 10 & 21 & 9 & 11 & 18 \\
\hline Portfolio development has helped me gain further insight into my approach to learning & 15 & 9 & 14 & 14 & 8 & 16 \\
\hline Portfolio assessment has helped me have a clearer understanding of my values. & 16 & 14 & 8 & 18 & 15 & 5 \\
\hline Portfolio development has helped me work in a group as a team member & 11 & 10 & 17 & 6 & 13 & 19 \\
\hline Portfolio assessment has contributed to my awareness of the need to support my peers & 9 & 15 & 14 & 9 & 14 & 15 \\
\hline Portfolio development has stimulated awareness of my decision making processes & 11 & 13 & 14 & 9 & 16 & 13 \\
\hline Portfolio development has provided opportunities to modify my approaches to learning & 11 & 11 & 16 & 8 & 14 & 16 \\
\hline Keeping a Learning Portfolio was stressful & 6 & 10 & 22 & 11 & 8 & 19 \\
\hline Keeping a Learning Portfolio was time consuming & 0 & 4 & 34 & 1 & 3 & 34 \\
\hline My portfolio is an individual expression of my learning process & 15 & 9 & 14 & 7 & 12 & 19 \\
\hline Portfolio development makes me feel accountable and responsible for my learning & 11 & 11 & 16 & 13 & 9 & 16 \\
\hline Portfolio development has contributed to my personal growth & 18 & 12 & 8 & 15 & 18 & 5 \\
\hline Portfolio development has contributed to my professional growth & 17 & 13 & 8 & 11 & 17 & 10 \\
\hline Portfolio development has contributed to my learning & 13 & 10 & 15 & 12 & 10 & 16 \\
\hline The purpose of the Learning Portfolio is clear & 5 & 10 & 23 & 6 & 5 & 27 \\
\hline My portfolio is a tangible expression of my ideas \& experience as a student learner in this course. & 11 & 12 & 15 & 12 & 10 & 16 \\
\hline Overall developing the Learning Portfolio has been a worthwhile experience & 11 & 15 & 12 & 13 & 11 & 14 \\
\hline
\end{tabular}

\section{Qualitative Questions}

1. What have you learned about the subject that you did not previously know as a result of keeping this learning portfolio?

2. What have you discovered about your learning style as a result of keeping this learning portfolio?

3. What are the best/weakest examples of your work in this learning portfolio?

4. What do your selection of the various content items and the portfolio overall reflect about your learning?

5. What new learning strategies have you adopted as a result of the portfolio process?

6. What were the most difficult part of the process? Why?

7. In what ways is your learning portfolio unique? How does it capture your personal learning experience and voice?

8 . What has been the most meaningful about the portfolio process? Why?

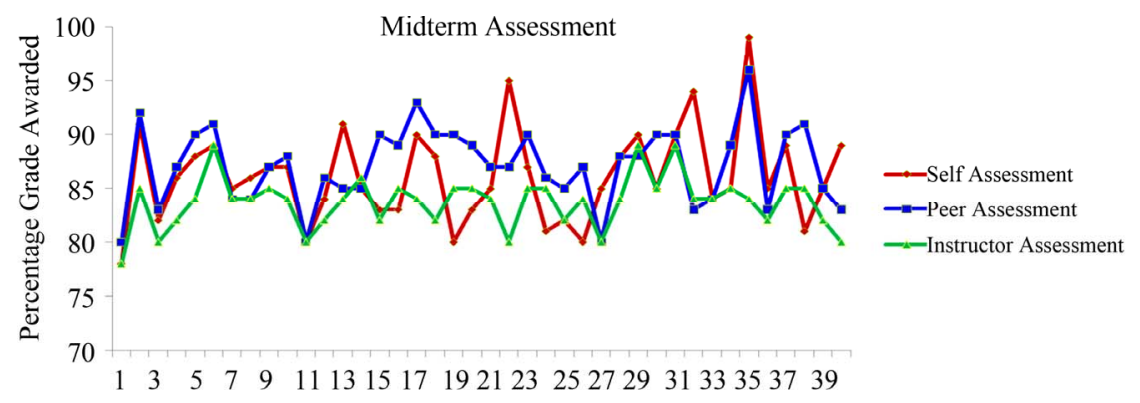

Figure 1.

Midterm assessment. This line-graph illustrates the percentage-grade of the learning portfolio awarded by the tripod panel of assessors at the midterm examination. The self-assessment grades are in red, the peer-assessment grades are in blue and the instructor-assessment grades are in green. The $y$-axis is the percentage grade awarded and the $\mathrm{x}$-axis is a single-point representation of each of the forty-one students. 
the midterm evaluation. Sample quotations from the qualitative self and peer feedback obtained are listed in Table 3. Some students provided one-sentence feedback, whereas others wrote an entire paragraph. The depth of insight offered ranged signifi- cantly, from vague comments on organization, grammar, and completion to analyses of specific portfolio elements. Interestingly, the majority of reported weaknesses by all three assessors were predominantly related to the self-reflection documents.

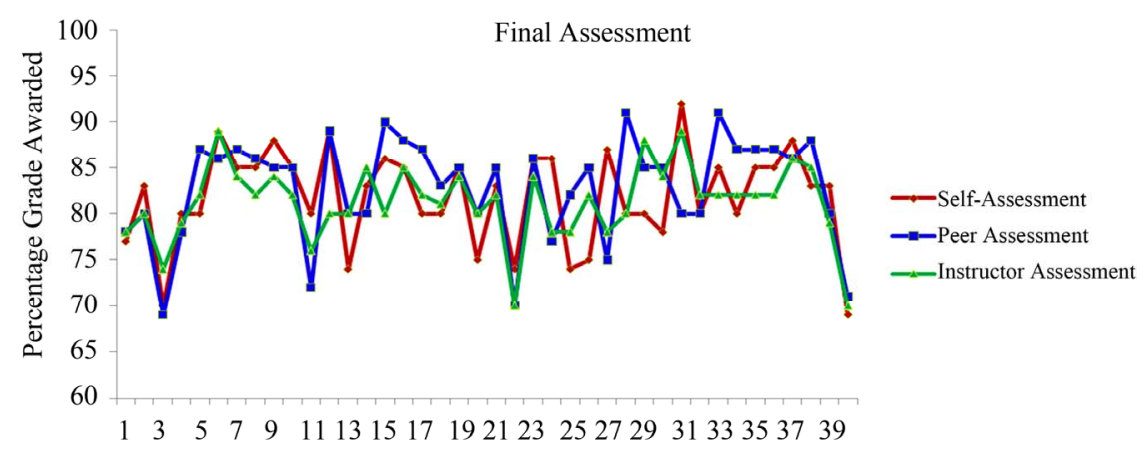

Figure 2.

Final assessment. This line-graph illustrates the percentage-grade of the learning portfolio awarded by the tripod panel of assessors at the end of the final examination. The self-assessment grades are in red, the peer-assessment grades are in blue and the instructor-assessment grades are in green. The $\mathrm{y}$-axis is the percentage grade awarded, and the $\mathrm{x}$-axis is a single-point representation of each of the forty-one students.

Table 3.

Examples of qualitative feedback from self and peer assessments.

- $\quad$ Portfolio Strengths

o SELF:

- "All mandatory elements are met"

- "As learning samples were added and reflection created, the completed entries were listed in a table of contents that is neat, organized, and ex-

plains the relevance of learning experience to myself"

- "Clear learning points, organized to include study notes that are an indication of what and how I really learned the material"

- "One of the strengths of my learning portfolio is that it is also an excellent study tool"

- "My reflections are truthful. I did not hold back my thoughts or feelings"

O PEER:

- "All required content is in the portfolio"

- "Easy to read, good grammar and sentence structure"

- "Well organized, clearly laid out, self-reflections are thorough and well thought out"

- "Straight to the point, no clutter, honest learning points"

- "It demonstrates dedication to learning and goes beyond the minimum required work"

- "The leaner is aware of his preferred learning styles and shows evidence of using them, with a willingness to be critical during reflections"

- Portfolio Weaknesses

o SELF:

- "The binder I purchased was too small"

- "My group poster from Module 6 is unprofessional and disappointing, decreasing the overall quality of my work"

- "The self-reflections were hard to write in my opinion, so they are not as reflective as they could have been"

- "Even though I did attempt other methods of learning and exploring course content, there is no evidence of it in my portfolio"

O PEER:

- "Formatting is not consistent throughout the portfolio"

- "Learning objectives were simply stated and not built upon"

- "Perhaps more insightful information could be made - for example, quizzes could have reasons why the answers are what they are"

- "Key learning points were there, however these questions were never actually answered in the portfolio"

- "Self-reflections are superficial. Add more components that will showcase learning efforts, including strengths and weaknesses of week’s learning"

- Recommendations for Portfolio Improvement:

o SELF:

- "Spelling corrections and adding more learning points"

- "Continue to focus reflections on overall learning as opposed to focusing on one class"

- "Use the portfolio as more of study tool rather than an assignment by answering the objectives, not just stating them"

- "I should take a couple minutes a week and look on the internet for some current events on the subject we are looking at or use other outside information to help clarify material”

O PEER:

- "Add table of contents at the beginning of each section for organization"

- "Incorporate learning objectives more evidently within each section to demonstrate grasping material"

- "Include evidence of diverse learning approaches. Eg- diagrams, sketches, mnemonics you create while studying"

- "Taking each of the points you make in your self-reflection and answering why you feel that way would make them more in-depth and helpful for you to make future strategies" 
Thirty-eight of the 41 students (93\%) responded to the midterm and final satisfaction questionnaires. Students' response to this educational activity improved as the course progressed. At midterm evaluation (Figure 3), one third (32\%) of the class responded favourably (at a level 4 - 5) to questions outlining the value of portfolio development within the various facets of learning, including organization, reflection, responsibility, group-work, stress and personal/professional growth. When these same questions were again posed at the final examination (Figure 4), nearly half (47\%) of students responded favourably, and a greater divide was seen among students who enjoyed this creative process and those that did not. Seven questions were identified that demonstrated a change in students' perspective and learner behaviour over the term (Table 2 -green background). These perceptions were:

1) Though at the midterm exam $61 \%$ (28 students) responded negatively (levels 1 - 2) when questioned about their perceived communication improvement, at final examination this number decreased to $48 \%$.

2) More students felt that the development of the portfolio helped to gain further insight into their approach to learning, increasing from $37 \%$ to $42 \%$.

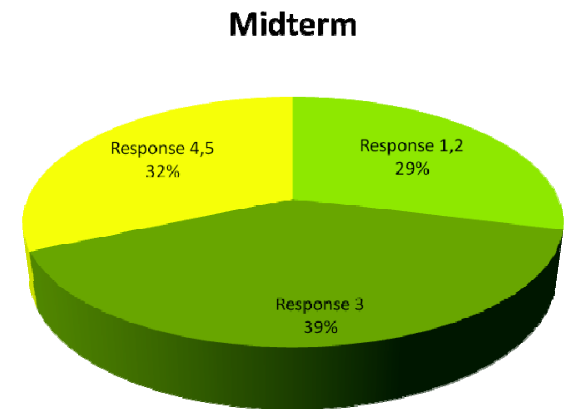

Figure 3.

Students' Midterm Evaluation of the Learning Portfolio. This pie-chart illustrates student perceptions at the midterm examination to the question "overall developing the learning portfolio has been a worthwhile expeence”. Response 1: Strongly disagree; Response 2: Disagree; Response 3: Neutral; Response 4: Agree; Response 5: Strongly agree.

Final

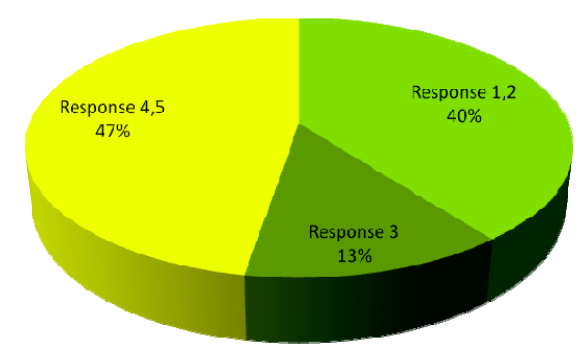

Figure 4.

Students' Final Evaluation of the Learning Portfolio. This pie-chart illustrates student perceptions at the end of the final examination to the question "overall developing the learning portfolio has been a worthwhile experience". Response 1: Strongly disagree; Response 2: Disagree; Response 3: Neutral; Response 4 : agree; Response 5: Strongly agree.
3) Portfolio development was perceived to enhance team work in $45 \%$ at the midterm, and $50 \%$ at the final examination.

4) A large increase, from $37 \%$ to $50 \%$ as a favourable response to this educational innovation is also reflected in the statement "My portfolio is an individual expression of my learning process".

5) At midterm students did not believe the portfolio contributed to professional growth (21\% levels 4 - 5); however, the final questionnaire was more positive (26\% levels 4 - 5).

6) Students found the purpose of the learning portfolio to be clear (61\% midterm, $71 \%$ final).

7) Overall students found the development of the learning portfolio to be a worthwhile experience.

As a part of the satisfaction questionnaires, students were posed eight open-ended qualitative questions (Table 2). A few of the student comments are summarized below.

In response to the first question (\#1) asking students what they had learned as a result of the learning portfolio, the majority of students focused on learning from class material and activities rather than the learning portfolio itself; however, some students commented that the portfolio aided in identifying effective learning techniques, and the challenges associated with integrating and organizing materials. Noteworthy comments include:

- "The portfolio allowed for engagement and learning within and outside of the classroom".

- "The portfolio helped me assess on an ongoing basis how well I am doing in meeting the subject/content knowledge goals of the course".

- "It helped me make connections between and see the relevance of knowledge and skills".

- "The portfolio allowed for engagement in learning within and outside of the classroom which allowed everyone to be independent of our learning, both individual and in dependent groups".

Responses to the second question (\#2) regarding the role their portfolio played in identification of learning styles yielded a wide variety of explanations of their personal optimal learning environment.

- "I have learned that I do not learn well in a group".

When asked to describe the best and weakest examples of their work included in the portfolio (question \#3), many students were proud of the "key learning points" and various in-class group activity products they had created specifically for the portfolio. The most common weakness was:

- "My self-reflections-I did not spend much time on them and did not go further than the questions on the template to evaluate my progress".

The fourth question was more personal, asking students what their portfolio contents reflect about their learning (\#4). Most of the responses outlined students' need for organization of materials, drive towards self-directed learning, and awareness of the variety of learning styles employed and appreciated.

The most common response when asked about new learning strategies adopted as a result of portfolio development (question \#5) was time management skills and the development of 'key learning points'. Despite their reluctance towards the reflection documents, students noted

- "I was surprised when I realized that taking time to reflect each week on courses is so important in order to assess what is working and what is not".

- "I am beginning to recognize that reflection is essential to 
learning; it fosters critical thinking, problem solving and decision making which is essential to continuous learning and improvements".

- "I now sit back and take a moment to evaluate what I need to do in order to be successful at learning".

Many students found the most difficult part of the portfolio process (question \#6) was in maintaining high-levels of motivation and finding the time to add documents, reflect, and personalize throughout the entire length of course:

- "Balancing my time and understanding that I can't do everything at the last minute".

Students additionally struggled with the self-reflection documents:

- "I had a great deal of trouble trying to reflect on what had gone right and wrong during the week and why it was so".

Students did note that by the second half of the semester:

- "I had a better idea of what to do and how and when to do it" "The most difficult part was being able to find relevant information on my own and choose what is relevant, with constant reflection to check up on myself and how the learning process is going".

Students were asked to reflect on unique characteristics of their portfolio (question \#7). Each student response was unique and individualized as it often described specific documents or organizational techniques.

- "Items I included in my portfolio reflect my personal interests-science, research and sports are curiosities of mine and this are reflected within these pages".

- "When doing the weekly self refection, I decided after the first week not to use the template and instead more freely reflect what I have found important and interesting during each week. The highly organized format and overall neatness are a reflection on my learning style and personality".

The final question (\#8) about the most meaningful aspect of this project generated the most comments, as students were eager to share their wide variety of experiences. Organization and context were the most meaningful aspects of portfolio development for many students. One student commented

- "It is great if you know details, but if you can't fit them all together in the bigger picture then they are not of much use".

Other common trends noted included time-management skills, active-learning, and self-reflections. Students commented:

- "My portfolio is both a story and a comprehensive record of my learning. Both the process and the product reflect learning”.

- "Being able to create my portfolio allowed me to take pride in my work".

- "It has been a valuable tool for me to review and understand the content of each module".

- "Being able to create my portfolio allowed me to take more pride in my work".

- "Probably the self-reflections-because they involve looking within and identifying one's strengths, weaknesses, and unique qualities. They are the most intimate part of the portfolio".

\section{Discussion}

A learning portfolio is a collection of student work aimed at evidencing learning and professional development. Students gather documentation of their learning activities through a variety of sources and then integrate this evidence together to gain a more comprehensive representation of their knowledge (Driessen \& Norman, 2008). Evidence should include work completed, feedback received, progress made, and reflections including plans to improve competence (Driessen, van Tartwijk, van der Vleuten, \& Wass, 2007). The creation of such a portfolio involves four distinct steps:

1) Students' reflection on the learning goals and personal achievements;

2) The collection of evidence of this learning through a wide variety of sources;

3) The selection of the most appropriate and convincing evidence;

4) Creating connections between this evidence to create a three-dimensional portrait of the student as a learner and as a professional.

The learning portfolio's function is therefore two-fold: product and process. As a final product, the learning portfolio is a documentation of all learning activities, which can then be subjected to formative and summative evaluation. Though it is the final portfolio-product that may be assessed, the importance of this educational tool remains in the portfolio-process, as the process of learning portfolios catalyzes the self-directed learning (Pitts, Coles, \& Thomas, 2001). Through the process of its creation, the learning portfolio encourages students to systematically reflect on their learning and analyze their actions, encouraging them to designate alternative choices that may not have been apparent in the initial "learning moment".

Before a learning portfolio can be adopted, it must first be adapted. We strongly advocate that the successful introduction of a learning portfolio depends highly on its structure. Without a guide, the portfolio may become a simple collection of documents with the absence of any cohesion (Amsellem-Ouazana, van Pee, \& Godin, 2006). It has been suggested that too much structure is more damaging than too little (Driessen, van Tartwijk, van der Vleuten, \& Wass, 2007). Four models of learning portfolio structures have been reported by Endacott et al. (Endacott, Gray, Jasper, McMullan, \& Miller, 2004).

1) The "shopping trolley" portfolio contains a collection of course material that lacks cohesion and does not link course learning goals to the presented evidence;

2) The "toast rack" portfolio is highly organized into separate sections with no overlying connections tying these discrete elements together;

3) The "spinal column" portfolio focuses on the course learning goals with pieces of evidence centered on it with reflections bringing multiple competencies together;

4) The "cake mix" portfolio integrates theory with practice under an overarching narrative that links evidence with goals and learning outcomes.

Determining the extent of structure to offer students in order to guide their creative process is a delicate procedure for instructors. Students require guidance through well-defined guidelines and learning goals; however, the degree of detail that should be conferred may be difficult to ascertain. With considerable structure comes the risk of reducing the learning portfolio to nothing more than a checklist, thus diminishing students' originality and reflection in the portfolio creation (Driessen, van Tartwijk, Vermunt, \& van der Vleute, 2003; Rees, Shepherd, \& Chamberlain, 2005; Rees, Shepherd, \& Chamberlain, 2005). Nevertheless, some degree of structure is necessary as too much freedom may lead to student confusion and frustration as seen by Driessen et al. in the use of portfolios in early 
undergraduate medical training (Driessen, van Tartwijk, Vermunt, \& van der Vleuten, 2003). In our study, learning portfolios were semi-structured, as students were given a list of weekly mandatory and a list of suggested "voluntary" documents for inclusion.

Health care curricula have been evolving to emphasize personal and professional development. These changes are accompanied by recent evolving "new" curriculum outcomes coupled with the goal of increased 'student-centered' teaching and learning. Assessment goals no longer seek to evaluate just knowledge but rather ongoing performance and competency (Elango, Jutti, \& Lee, 2005). Unlike "grades" which may be considered an achievement, competency is an ongoing habit of learning and improvement; therefore assessment in higher education such as medicine must include student performance and capacity to adapt to change, find and generate new knowledge and improve overall performance (Epstein, 2007). Such a multifaceted, ambitious goal cannot be met by the traditional means of assessment, thereby necessitating alternative teaching strategies with valid and reliable assessment tools. Portfolio-based learning adheres to such teaching goals, and is grounded in the cyclical process of recording, reviewing, reflecting, and learning (Elango, Jutti, \& Lee, 2005). The learning portfolio's ability to richly evidence students' development and achievements separates this tool from other methods of assessment (Driessen, Overeem, van Tartwijk, van der Vleuten, \& Muijtjens, 2006). Unlike traditional educational tools that evaluate the students' possession of knowledge, portfolio assessment is a judgement of knowledge application and is therefore a complex task. Traditionally, difficult to evaluate qualities such as one's attitude, personal growth, reflective ability, professionalism, self-directed learning, and aptitude for self-development as required in health professional curricula are additional potential targets in portfolio assessment (David, Davis, Harden, Howie, Ker, \& Pippard, 2001; Davis, Ben-David, Harden, Howie, Ker, McGhee et al., 14). The personalized nature of the portfolio creates difficulty in assessment, as each is unique in content, size, and structure. Reliance on the personal judgements of the assessor is thus advocated as a detailed checklist trivializes the character of the assignment (Driessen, Overeem, van Tartwijk, van der Vleuten, \& Muijtjens, 2006).

The currently accepted educational paradigm in the training of health care professionals has adopted the constructivist model, in which students are independently responsible for "building" their own knowledge (Langendyk, 2006). Such self-regulated learning necessitates continual self-assessment, in which personal evaluation is intrinsically driven by the student with the ultimate goal of self-improvement. Many studies in the literature suggests that self-assessment by physicians is often inaccurate (Galbraith, Hawkins, \& Holmboe, 2008; Davis, Mazmanian, Fordis, Van Harrison, Thorpe, \& Perrier, 2006). It has been noted that higher-achievers will often underestimate themselves whereas those at a lower-level of aptitude tend to give themselves significantly higher ratings (Langendyk, 2006; Galbraith, Hawkins, \& Holmboe, 2008). During training the majority of physicians are not exposed to effective self-assessment tasks, which may perhaps account for these discrepancies later in practice. Self-assessment is an important skill, aimed at increasing self-improvement activities including appraisal of strengths/weaknesses and setting appropriate personal goals (Galbraith, Hawkins, \& Holmboe, 2008). Introduction of selfassessment may offer students the opportunity to practice and develop this skill as seen in the study of the introduction of self-reflection assignments in the early years of undergraduate medical education (Kanthan \& Senger, 2011). Factors including clear learning goals, feedback provision, and external evaluative data may contribute to the improvement of this practice in the training of health professionals (Gordon, 1991). It has been suggested that self-assessment may further be enhanced through external validation, which may include peer-feedback (Galbraith, Hawkins, \& Holmboe, 2008).

Peer-feedback is a powerful, insightful, and instructive tool reported to promote communication, teamwork, and professionalism so long as feedback provided is constructive, confidential, and the source is deemed credible (Epstein, 2007). In health care, peer-assessment has infiltrated into nearly all aspects of professional competence (Norcini, 2003). Within the educational context, a "peer" may be someone at the same level of education, or a senior student. Twelve distinct benefits supporting peer-teaching in medical education have been listed by Ten Cate and Durning (Ten Cate \& Durning, 2007). These include: 1) alleviating teaching pressure for faculty; 2) offering education at students' own cognitive level; 3) creating a comfortable and safe educational environment; 4) socializing students and providing role models; 5) offering an alternate study method and motivation; 6) enhancing intrinsic motivation, 7) preparing physicians for an educator's role; 8) incorporating this assessment as part of a multisource feedback; 9) training leadership skills and increasing confidence; 10) modifying academic culture to accept education as a core task of healthcare; 11) sustaining training programs in low-resource settings; and 12) offering supervision responsibility to trainees. Key factors that may influence the quality of the assessment include reliability (the number of performances assessed and competencies to be evaluated), relationships (students in competition vs. friends), stakes (anonymity of evaluator may be beneficial), and equivalence (in status and education between the student and the peer) (Norcini, 2003). When implemented correctly, peerassessment can provide a unique learning opportunity for both the assessor and the assessed.

In the assessment of a learning tool as highly personalized as the portfolio, there is an inherent risk that students may specially choose evidence and direct their reflections and portfolio contents towards what they believe will earn them the highest grades rather than reflecting on weaknesses, commonly referred to as "the corruption of portfolios for testing purposes" (Endacott, Gray, Jasper, McMullan, Miller, Scholes, \& Webb, 2004; Driessen, Van Tartwijk, Vermunt, \& van der Vleuten, 2003). This teaching/learning tool may be concurrently assessed through both formative and summative means, by continued monitoring with feedback, as students progress through different phases of their education (Driessen, van Tartwisj, van der Vleuten, \& Wass, 2007; Davis, Ben-David, Harden, Howie, Ker, McGhee, Pippard, \& Snadden, 2001). The combination of formative assessment linked with summative decisions creates a powerful assessment tool (David, Davis, Harden, Howie, Ker, \& Pippard 2001). Unlike traditional multiple-choice, short-answer or essay questions, portfolio creation is an ongoing process that encourages revision, reflection, and trial-and-error learning (Pitts, Coles, \& Thomas, 2001). It is a well-recognized fact that assessment drives learning (Driessen, van Tartwijk, Vermunt, \& van der Vleuten, 2003); therefore, summative evaluation is a key component of the learning portfolio to assure that the portfolio maintains its importance alongside other assessment tools 
(Driessen, van Tartwijk, van der Vleuten, \& Wass, 2007).

The use of learning portfolios as an assessment tool in high stakes decision-making such as medical education requires it to be rooted in sound psychometric properties (Roberts, Newble, \& O’Rourke, 2002). The literature has yet to come to a consensus on the reliability and validity in the assessment of this teaching/learning tool. A comprehensive review of the literature conducted by Driessen et al. of portfolios in medical education observed a trend of high inter-rater reliability in recent studies. In this study, reliability appeared to be related to certain factors, including the use of a small group of trained assessors that discussed and graded the student work using a holistic scoring rubric (Driessen, van Tartwijk, van der Vleuten, \& Wass, 2007). In contrast, a study by Roberts et al. on portfolio-based assessments in medical education identified a rater-reliability well below the acceptable value (Roberts, Newble, \& O'Rourke, 2002). It is suggested that reliability may be improved by 1 ) semi-standardization of the portfolio; 2) analytical objective assessment; and 3) an increased number of assessors (Driessen, Van Tartwijk, Vermunt, \& van der Vleuten, 2003). Reliability may further be enhanced by consensus-building discussion between two independent assessors, yielding high levels of agreement on both objective and subjective criteria (Driessen, Overeem, van Tartwijk, van der Vleuten, \& Muijtjens, 2006). Unfortunately, a standardized, reductionist format optimal for increased reliability impinges on the validity of portfolio assessment. It has been suggested that methods such as standardization that may improve reliability could jeopardize validity, as students would no longer experience freedom to the same extent (David, Davis, Harden, HOwie, Ker, \& Pippard, 2001; Driessen, van Tartwijk, van der Vleuten, \& Wass, 2007; Driessen, van Tartwijk, Vermunt, \& van der Vleuten, 2003). The validity of portfolio assessment is related to the evaluator's interpretation, expectations, and understanding of the learning goals. As such, greater validity can be achieved when the evaluator is familiar with the educational program and student progression (David, Davis, Harden, Howie, Ker, \& Pippard, 2001). Promising results were found in a study examining factors that influence evaluator's judgement of student reflective skills, as it was determined that the quality of reflection was the only factor to significantly contribute to the evaluation, with features such as lay-out, spelling/grammar and structure being not significant to the overall grade awarded (Driessen, Overeem, van Tartwijk, van der Vleuten, \& Muijtjens, 2006).

The drivers and benefits of implementing learning portfolios are numerous. The promotion of self-reflection with the identification of personal strengths and weaknesses within the context of professional practice is the greatest strength of this teaching technique (Pitts, Coles, \& Thomas, 2001). Reflection can be stimulated as students gather, organize, and analyze documented evidence of learning for inclusion in the portfolio (Driessen, van Tartwijk, van der Vleuten, \& Wass, 2007). Portfolio-learning is authentic, in that it incorporates evidence of past academic and work-related experiences that act as a foundation for new knowledge (David, Davis, Harden, Howie, Ker, \& Pippard, 2001). As such, portfolio assessment focuses on the quality of ongoing work rather than examination performance, showcasing students' abilities within the context of their talents, interests, and potentials. As this learning is highly personalized, self-directed, and student-centered, learners autonomously assess individual strengths and weaknesses with identification of learning needs (Rees, Shepherd, \& Chamberlain, 2005). By consequence, the nature of the teacher-student interactions is shifted, as students become increasingly independent. As evidenced by their comments, students found the self-reflection document to be one of the weakest and most difficult aspects of this portfolio creation, yet recognized that it was a valuable learning strategy and a meaningful learning experience. This assessment tool is additionally useful in:

1) Increasing student engagement, and active learning;

2) Linking experience with reflection and interpretation, thereby contextualizing learning;

3) Providing an alternative method of self-assessment;

4) Practicing and facilitating written and verbal communication skills;

5) Promoting independent self-directed, situated, authentic, lifelong learning;

6) Providing an enhanced student learning environment;

7) Enhancing skills including time management, organization, and decision making.

The challenges and barriers of the learning portfolio lie in students' unfamiliarity with this educational tool, and the perceived large workload for both the learner and the assessor (Pitts, Coles, Thomas, 2001). As such, it is paramount that both the students and educators understand and acknowledge the reasons for portfolio development and what the process entails (van Tartwijk, Driessen, van der Vleuten, \& Stokking, 2007). Completion and assessment of learning portfolios is a large time-commitment due to the widespread amount of material and extensive reflection required for its completion. In our study, students commented "it takes up far too much time" and "what on earth am I to put in this self-reflection report?" Though it is meant to be a weekly activity, students may be tempted to procrastinate until the due date nears at which point the portfolio may be assembled in a haste, without reflection or learning. If students do not recognize and/or accept the inherent value of this learning tool, and are unclear in its purpose, comments such as "how can this be useful to me as a doctor?" can occur, as seen in some of the student comments in our study. The primary barrier, however, remains the uncertainty regarding the value in maintaining a learning portfolio, with the central question "is this worth all this effort?" Though a large body of research supports an affirmative response, in our opinion further validation is required to universalize this opinion.

\section{Conclusion}

Integration of learning portfolios in all levels of education and post-educational accreditation is increasing throughout multiple disciplines. The portfolio's centricity on the "self"self-reflection, self-direction, self-discipline and self-assessment-makes it a valuable educational activity in the constructivist educational community. Though traditionally assessment of learning portfolios has relied on qualitative/formative feedback, its use in higher-stakes decision-making necessitates the development of a quantitative/summative means of assessment. A challenge in the use of this educational strategy as an assessment tool lies in balancing the conflict between holistic personalization and true reflection versus objective standardization of assessment as validation for the grade/marks awarded. Self-, peer-, and instructor-evaluation are individually wellstudied assessment techniques in the literature; however, to the best of our knowledge this "synchronous tripod of assessment" has not been evaluated within the context of learning portfolios. 
Reflection on our study authenticates that the combination of formative and summative evaluations from such synchronous tripod assessments of learning portfolios is particularly suited for inclusion in higher education including undergraduate and post-graduate medical education and allied health professions.

\section{Acknowledgements}

This project was completed with the help of a TeacherScholar Grant Aid from the University of Saskatchewan.

\section{REFERENCES}

Amsellem-Ouazana, D., Van Pee D., \& Godin, V. (2006). Use of portfolios as a learning and assessment tool in a surgical practical session of urology during undergraduate medical training. Medical Teacher, 28, 356-359. doi:10.1080/01421590600628100

David, M. F. B., Davis, M. H., Harden, R. M., Howie, P. W., Ker, J., \& Pippard, M. J. (2001). AMEE medical education guide no. 24: Portfolios as a method of student assessment. Medical Teacher, 23, 535551. doi:10.1080/01421590120090952

Davis, D. A., Mazmanian, P. E., Fordis, M., Van Harrison, R., Thorpe K. E., \& Perrier, L. (2006) Accuracy of physician self-assessment compared with observed measures of competence. The Journal of the American Medicine Association, 296, 1094-1102. doi:10.1001/jama.296.9.1094

Davis, M. H., Ben-David, M. F., Harden, R. M., Howie, P., Ker, J., McGhee, C., Pippard, M. J., \& Snadden, D. (2001) Portfolio assessment in medical students' final examinations. Medical Teacher, 23, 357366. doi:10.1080/01421590120063349

Driessen, E., \& Norman, G. (2008). Are learning portfolios worth the effort? British Medical Journal, 337, 320-321. doi:10.1136/bmj.39540.415822.AD

Driessen, E., Overeem, K., van Tartwijk, J., van der Vleuten, C. P. M., \& Muijtjens, A. M. M. (2006). Validity of portfolio assessment: Which qualities determine ratings? Medical Education, 40, 862-866. doi:10.1111/j.1365-2929.2006.02550.x

Driessen, E., van Tartwijk, J., van der Vleuten, C., \& Wass, V. (2007). Portfolios in medical education: Why do they meet with mixed success? A systematic review. Medical Education, 41, 1224-1233. doi:10.1111/j.1365-2923.2007.02944.X

Driessen, E., Van Tartwijk, J., Vermunt, J., \& van der Vleuten, C. (2003). Use of portfolios in early undergraduate medical training.
Medical Teacher, 25, 18-23. doi:10.1080/0142159021000061378

Elango, S., Jutti, R. C., \& Lee, L. K. (2005). Portfolio as a learning tool: Students’ perspective. Annuals Academy of Medicie, 24, 511-514.

Endacott, R., Gray, M. A., Jasper, M. A., McMullan, M., Miller, C., Scholes, J., \& Webb, C. (2004). Using portsolios in the assessment of learning and competence: The impact of four models. Nurse Education in Practice, 4, 250-257. doi:10.1016/j.nepr.2004.01.003

Epstein, R. M. (2007). Assessment in medical education. The New England Journal of Medicine, 356, 387-396. doi:10.1056/NEJMra054784

Galbraith, R. M., Hawkins, R. E., \& Holmboe, E. S. (2008). Making self-assessment more effective. Journal of Continuing Education in the Health Professions, 28, 20-24. doi:10.1002/chp.151

Gordon, M. (1991) A review of the validity and accuracy of self assessment in health professions training. Academic Medicine, 66, 762769. doi:10.1097/00001888-199112000-00012

Kanthan, R., \& Senger, J. L. (2011). An appraisal of students’ awareness of "self-reflection" in a first-year pathology course of undergraduate medical/dental education. BMC Medical Education, 11.

Langendyk, V. (2006). Not knowing that they do not know: self-assessment accuracy of third-year medical students. Medical Education, 40, 173-179. doi:10.1111/j.1365-2929.2005.02372.x

Norcini, J. J. (2003). Peer assessment of competence. Medical Education, 37, 539-543. doi:10.1046/j.1365-2923.2003.01536.x

Pitts, J., Coles, C., \& Thomas, P. (2001). Enhancing reliability in portfolio assessment: "Shaping” the portfolio. Medical Teacher, 23, 351356. doi:10.1080/01421590120057021

Rees, C. E., Shepherd, M., \& Chamberlain, S. (2005) The utility of reflective portfolios as a method of assessing first year medical students' personal and professional development. Reflective Practice, 6, 3-14. doi:10.1080/1462394042000326770

Roberts, C., Newble, D. I., \& O’Rourke, A. J. (2002). Portfolio-based assessments in medical education: Are they valid and reliable for summative purposes? Medical Education, 36, 899-900. doi:10.1046/j.1365-2923.2002.01288.x

Ten Cate, O. T., \& Durning, S. (2007). Peer teaching in medical education: Twelve reasons to move from theory to practice. Medical Teacher, 29, 591-599. doi:10.1080/01421590701606799

Teng, C. L. (2007). Portfolio assessment. Malaysian Family Physician, 2, $125-126$.

van Tartwijk, J., Driessen, E., van der Vleuten, C., \& Stokking, K. (2007). Factors influencing the successful introduction of portfolios. Quality in Higher Education, 13, 69-79. doi:10.1080/13538320701272813 